\title{
Smelowskia sunhangii (Brassicaceae), a new species from China, with a re-evaluation of the $S$. tibetica complex
}

\author{
Xin-jian Zhang' ${ }^{*}$, Jun-Tong Chen 1,2*, Ihsan A. Al-Shehbaz ${ }^{3}$, Qun Liu', \\ Li-Juan Li ${ }^{1,2,5}$, Peng-Ju Liu', Xian-Han Huang', Tao Deng'
}

I CAS Key Laboratory for Plant Diversity and Biogeography of East Asia, Kunming Institute of Botany, Chinese Academy of Sciences, Kunming 650201, Yunnan, China 2 University of Chinese Academy of Sciences, Beijing 100049, China 3 Missouri Botanical Garden, 4344 Shaw Blvd., St. Louis, Missouri 63110, USA 4 School of Life Sciences, Yunnan Normal University, Kunming 650092, Yunnan, China 5 CAS Key Laboratory of Plant Germplasm Enhancement and Specialty Agriculture, Wuhan Botanical Garden, Chinese Academy of Sciences, Wuhan 430074, Hubei, China

Corresponding author: Tao Deng (dengtao@mail.kib.ac.cn)

Academic editor: Karol Marhold | Received 8 January 2021 | Accepted 30 April 2021 | Published 4 June 2021

Citation: Zhang X-j, Chen J-T, Al-Shehbaz IA, Liu Q, Li L-J, Liu P-J, Huang X-H, Deng T (2021) Smelowskia sunhangii (Brassicaceae), a new species from China, with a re-evaluation of the S. tibetica complex. PhytoKeys 178 : 179-191. https://doi.org/10.3897/phytokeys.178.62922

\begin{abstract}
Smelowskia sunhangii, from Qinghai and Tibet (China), is described and illustrated. Morphological and molecular data indicate that $S$. sunhangii is closely related to Smelowskia tibetica, from which it is easily distinguished by the densely hirsute (vs. glabrous or sparsely pubescent), elliptic to ovate-lanceolate (vs. suborbicular, oblong, or lanceolate) fruits with undulate (vs. straight) margins. A re-evaluation of the widely distributed $S$. tibetica and related taxa is also provided.
\end{abstract}

\section{Keywords}

Brassicaceae, China, Cruciferae, new species, phylogeny, taxonomy

* The authors contributed equally to this study.

Copyright Xin-jian Zhang et al. This is an open access article distributed under the terms of the Creative Commons Attribution License (CC BY 4.0), which permits unrestricted use, distribution, and reproduction in any medium, provided the original author and source are credited. 


\section{Introduction}

The genus Smelowskia C.A.Mey. (Brassicaceae; Cruciferae) comprises 25 species distributed mainly in central and northeastern Asia, with fewer species in North America (Al-Shehbaz and Warwick 2006). The North American-Beringian taxa are believed to have originated from Asian ancestors (Carlsen et al. 2010). However, as in many other genera of the family, Smelowskia lacks unique synapomorphies (Warwick et al. 2004), though it is currently placed in the monogeneric tribe Smelowskieae (Al-Shehbaz et al. 2006; Al-Shehbaz 2012). Schulz (1936) and Appel and Al-Shehbaz (2003) considered the genera Ermania Cham. ex Botsch., Gorodkovia Botsch. \& Karav., Hedinia Ostenf., Redowskia Cham. \& Schltdl., Sinosophiopsis Al-Shehbaz, and Sophiopsis O.E. Schulz to be morphologically closely related to Smelowskia. Warwick et al. (2004) and AlShehbaz and Warwick (2006) incorporated all these genera into Smelowskia based on molecular phylogenetic and morphological evidences.

Nine species of Smelowskia are native to China (Al-Shehbaz and Warwick 2006; German and Chen 2009), and they are distributed mainly in the western parts of the country. In their most recent account for the Flora of China, these species were placed by Zhou et al. (2001) in the genera Hedinia, Sinosophiopsis, Smelowskia, and Sophiopsis. Of these, H. tibetica (Thomson) Lipsky is the most widely distributed (Bhutan, W and Himalayan China, India, Kyrgyzstan, Nepal, Tajikistan) and was recognized by these authors as most highly variable in fruit shape. Four new taxa were described by Zhou and An (1990) and He and An (1996) from Xinjiang province, including H. lata Xue L.He \& C.H.An, $H$. rotundata C.H.An, $H$. taxkargannica G.L.Zhou \& C.H.An, $H$. taxkargannica var. hejigensis G.L.Zhou \& C.H.An, but these were reduced by Zhou et al. (2001) and Al-Shehbaz and Warwick (2006) to synonymy of Smelowskia tibetica (Thomson) Lipsky based on the examination of all type collections of Smelowskia. The above Smelowskia tibetica complex is re-examined here in light of additional field and molecular studies.

During a recent field survey, we collected an unidentified specimen of Smelowskia in Qinghai province, China (Fig. 1), and it appeared initially to be allied morphologically to the $S$. tibetica complex. The current study is devoted to resolve the mystery of the Chinese components of this complex.

\section{Materials and methods}

\section{Morphological observation}

Morphological data were recorded from field collections and herbarium specimens covering the full spectrum of geographical, plant type, and habitat variation in the $S$. tibetica complex. The voucher specimens of our collections were deposited in the herbarium of Kunming Institute of Botany (KUN), Kunming, China. Herbarium specimens of the $S$. tibetica complex and related taxa were examined from BNU, KUN, PE, 


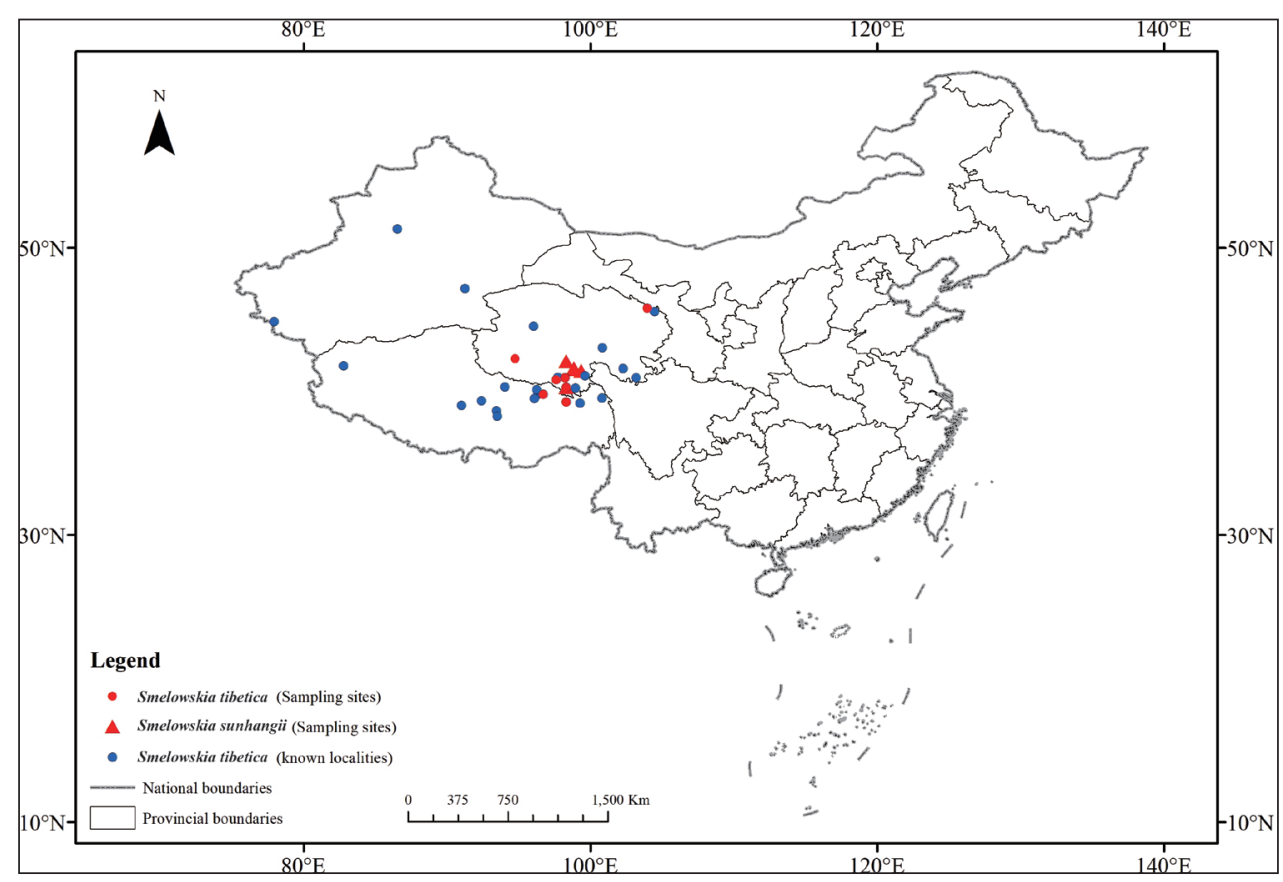

Figure I. Distributions of sampling sites (red triangles) of Smelowskia sunhangii, known localities (blue dots) and sampling sites (red dots) of Smelowskia tibetica in China.

WUK and XJA (acronyms follow Thiers 2018), either by examining the specimens directly, or electronically through the National Plant Specimen Resource Center (http:// www.cvh.ac.cn/index.php), and JSTOR Global Plants web portal (https://plants.jstor. org/). The voucher specimens for morphological observation were cited in the section of "Chinese specimens examined" of taxonomic treatment and Table 1.

\section{Molecular analyses}

We sampled 12 collections representing the Smelowskia tibetica complex, including the presumed new species. Leaf materials were collected from field works and dried herbarium specimens. Descurainia pinnata from tribe Descurainieae (sister to tribe Smelowskieae) and Shehbazia tibetica from tribe Chorisporeae were selected as outgroups based on previous molecular phylogenetic relationships (Warwick et al. 2004; Al-Shehbaz et al. 2006; Al-Shehbaz 2012; Liu et al. 2020). Sequences for other taxa were obtained from GenBank (Table 1). Voucher information and GenBank accession numbers are also provided in Table 1.

Total genomic DNA extracted from leaf materials using DP305 Plant Genomic DNA kits (Tiangen, Beijing, China) following the manufacturer's protocol. The entire ITS region (including internal transcribed spacers ITS1 and ITS2 of nuclear ribosomal DNA and the 5.8S rRNA gene) were amplified using the primers ITS1-18S described 
Table I. Voucher information and GenBank accessions for phylogenetic analysis.

\begin{tabular}{|c|c|c|}
\hline Taxon & Voucher & GenBank accession number \\
\hline Smelowskia tibetica (1) (as Hedinia rotundata) & Yang Jingsheng 402 (KUN) & MZ089467 \\
\hline S. tibetica (2) (as Hedinia lata) & HuangXH018-9 (KUN) & MZ089476 \\
\hline S. tibetica (4) (as H. lata) & HuangXH015-20 (KUN) & MZ089475 \\
\hline S. tibetica (5) (as H. lata) & Deng7359 (KUN) & MZ089474 \\
\hline S. tibetica (6) (as H. tibetica) & ZDG23-7 (KUN) & MZ089468 \\
\hline S. tibetica (7) (as H. tibetica) & Deng7261 (KUN) & MZ089473 \\
\hline S. sunhangii (1) & Deng7262 (KUN) & MZ089472 \\
\hline S. sunhangii (3) & DengT128-9 (KUN) & MZ089471 \\
\hline S. sunhangii (4) & HuangXH025-13 (KUN) & MZ089470 \\
\hline S. sunhangii (5) & DengT105-23 (KUN) & MZ089469 \\
\hline Shehbazia tibetica & HuangXH028-4 (KUN) & MZ089466 \\
\hline \multicolumn{3}{|l|}{ Sequences downloaded from NCBI } \\
\hline Smelowskia sunhangii (2) (as S. tibetica) & Zh641 (KUN) & KX244397 \\
\hline S. tibetica (3) (as H. lata) & LJQ-QLS-2008-0115 (KUN) & JF941772 \\
\hline S. czukotica & TCO3_60 & EU489520 \\
\hline S. altaica & TC03_61 & EU489519 \\
\hline S. bartholomewii & Ho et al. 3000 (MO) & AY230609 \\
\hline S. sophiifolia & Geonova 148 (LE) & AY230608 \\
\hline S. calycina & Velychnin N495 (LE) & AY230604 \\
\hline S. borealis & Murray $8582(\mathrm{DAO})$ & AY230571 \\
\hline S. jacutica & Elias \& Murray 11462 (ALA) & AY230646 \\
\hline S. johnsonii & Johnson, Viereck, \& Melchior 688 (ALA) & AY230631 \\
\hline S. ovalis & $C C D B-23367-G 06$ & MG234816 \\
\hline S. sisymbrioides & Egorova 2349 (LE) & AY230612 \\
\hline S. annua & Anonymous 870473 (HNWP) & AY230610 \\
\hline Descurainia pinnata & - & AF183122 \\
\hline Shehbazia tibetica (as Dontostemon tibeticus) & GH:33576 & LN713849 \\
\hline
\end{tabular}

in O'Kane et al. (1997) and ITS4 described in White et al. (1990). Parallel chromatograms derived from bi-directional sequencing were checked for accuracy by visual inspection with Chromas v. 2.6.6 (http://www.technelysium.com.au) and integrated into a single sequence. Sequences were then aligned with MEGA version 7.0 and gaps were treated as missing data (Sudhir et al. 2016).

Phylogenetic reconstruction was performed using Bayesian inference (BI) and maximum likelihood (ML). The phylogenetic tree based on Bayesian inference was generated using MrBayes version 3.2.6 (Huelsenbeck and Ronquist 2001). The phylogenetic analysis based on maximum likelihood was conducted with PhyML version 3.0 (Guindon et al. 2010). Detected by the jModeltest 2.1.7, the GTR+G model selected by Akaike information criterion (AIC) was used in BI and ML analyses (Posada 2008).

\section{Results}

\section{Morphology and taxonomy}

Morphological studies of strictly Chinese material revealed a wide variation in fruit indumentum and shape and leaf divisions in the Smelowskia tibetica complex, and such 


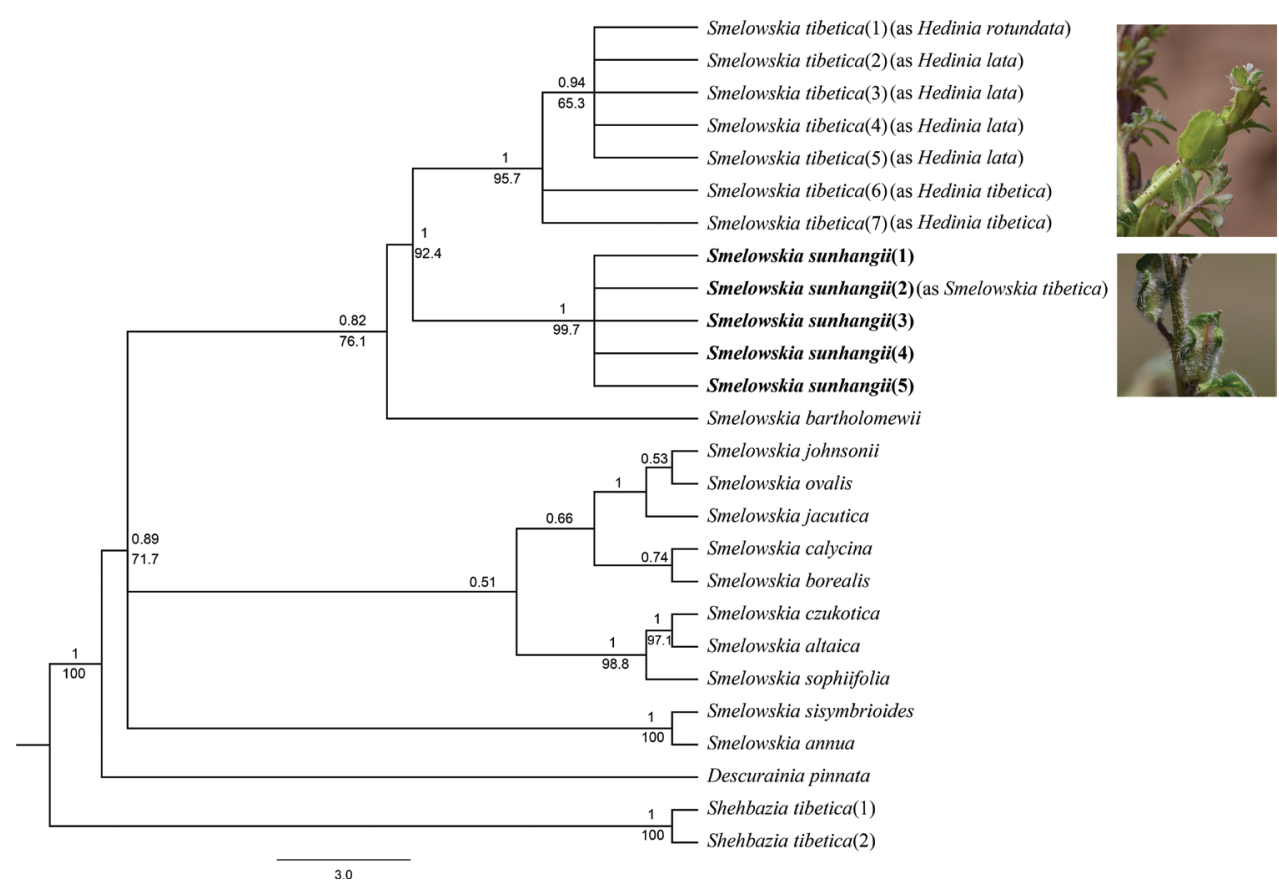

Figure 2. Bayesian consensus tree of 13 species of Smelowskia based on their ITS sequences, with Descurainia pinnata and Shehbazia tibetica as the outgroup. Numbers above branches indicate Bayesian posterior probability, numbers below branches are ML bootstraps.

differences lead Zhou and An (1990) and He and An (1996) to recognize several novelties under the synonymized Hedinia. For example, plants with 1- or 2-pinnatifid leaves and oblong glabrous fruits characterize the type collection of Smelowskia tibetica, those with 2-pinnatifid leaves and glabrous oblong fruits are found in the type of $H$. lata, those with lanceolate glabrous fruits are in plants of the type of $H$. taxkargannica, and those with pubescent suborbicular fruits are seen in the type of $H$. rotundata. All of the above taxa do not resemble the densely fruited plants we collected in Qinghai (Table 2).

These densely hirsute plants with densely hirsute, elliptic to ovate-lanceolate fruits undulate along the margin, do not match any of the other 25 species we carefully studied throughout the range of Smelowskia. Therefore, these Qinghai plants are described as the new species $S$. sunhangii and recognized hereafter as such.

\section{Phylogenetic analyses}

A total of 15 taxa were included in this analysis (Fig. 2). The resulting multiple alignment of the ITS region, including $5.8 \mathrm{~S}$ gene, was $651 \mathrm{bp}$. The $50 \%$ majority-rule consensus tree based on Bayesian posterior probability (PP) and maximum likelihood bootstraps (ML) of the ITS sequences both showed that four accessions of Smelowskia sunhangii grouped together $(\mathrm{PP}=1, \mathrm{ML}=99.7)$, however, an accession of previously 
Table 2. Comparison of selected distinguishing features of Smelowskia sunhangii and related taxa.

\begin{tabular}{lcccc}
\hline \multicolumn{1}{c}{ Taxon } & Cauline leaf shape & Fruit shape & Indumentum in silicle & Distribution \\
\hline Smelowskia tibetica & 1- or 2-pinnatifid & oblong & Glabrous & Qinghai, Tibet, Xinjiang \\
S. tibetica (as Hedinia lata) & 2-pinnatifid & oblong & Glabrous & Qinghai, Tibet, Xinjiang \\
S. tibetica (as H. taxkargannica) & 1-or 2-pinnatifid & lanceolate & Glabrous & Xinjiang \\
S. tibetica (as H. rotundata) & 1-pinnatifid & suborbicular & sparsely pubescent & Xinjiang \\
S. sunhangii & 1-pinnatifid & elliptic to ovate-lanceolate & densely hirsute & Qinghai, Tibet \\
\hline
\end{tabular}

determined Smelowskia tibetica (KX244397) was nested in it. After a critical examination of the voucher of this accession, Zh641 (KUN), we immediately concluded that it is $S$. sunhagii.

All of the seven accessions of the Smelowskia tibetica complex formed a monophyletic clade, sister to $S$. sunhangii with a strong support $(\mathrm{PP}=1, \mathrm{ML}=95.7)$. In addition, the clade of Smelowskia tibetica complex formed a polytomy of three subclades, of which two belong to Smelowskia tibetica and the third is a polytomy of samples identifiable as members of the Hedinia lata and H. rotundata as characterized morphologically above.

\section{Discussion}

Our molecular and morphological analyses indicate that Smelowskia tibetica sensu lato contains two, easily distinguished species, of which one is the new $S$. sunhangii and the other is S. tibetica including the taxa described by Zhou and An (1990) and He and An (1996) as three species and one variety of Hedinia. Although our data show some differentiation within S. tibetica, namely a polytomy of the Hedinia taxa forming another polytomy with the remaining samples of S. tibetica proper, such a current slight differentiation does not justify the recognition of more than two species. The principal reasons for not recognizing the Hedinia taxa are as follows.

First and foremost, as discussed above in the section of "Morphology and taxonomy" of the results, the variation in leaf and fruit morphology in the entire Smelowskia tibetica complex was critically studied by one of us (Al-Shehbaz) in plants from the entire range of this complex in Bhutan, India, China, Nepal, and Tajikistan both in herbaria worldwide and in the field in Xinjiang (China), Nepal, and Tajikistan. The conclusion of such observations was the acceptance of a single polymorphic species in the Himalayan region (Al-Shehbaz 2015), including Nepal and its neighbors (Al-Shehbaz and Watson 2011). That conclusion was also reflected in BrassiBase (Kiefer et al. 2014), the comprehensive and continuously updated database on the entire Brassicaceae.

Then similar variation in fruit and leaf morphology of the Smelowskia tibetica complex, especially that of the Hedinia taxa discussed above, was observed sporadically elsewhere in the species range and, therefore, the alleged distinction of Hedinia taxa has no merit.

Additionally, although our molecular data show a slight differentiation in the Hedinia taxa (Fig. 2), our sampling cannot be considered as the final word without 
doing similar analyses from the other countries where Smelowskia tibetica grows. We only used just two samples of this highly variable and widespread species. Therefore, the most reasonable conclusion is to avoid the recognition of any of the Hedinia taxa and create additional synonymies without more convincing data.

Finally, our morphological studies strongly support the novelty of Smelowskia sunhangii because its fruit morphology in unique in the genus and has not yet been observed in Asian and North American taxa. Furthermore, our molecular data also strongly support the above recognition of the novelty and its sister relationship to $S$. tibetica including the Hedinia taxa of Zhou and An (1990) and He and An (1996).

\section{Taxonomic treatment}

\section{Smelowskia sunhangii T. Deng, X.J. Zhang \& J.T. Chen, sp. nov.} urn:Isid:ipni.org:names:77217427-1

Figs 3, 4

Type. China. Qinghai. Yushu Tibetan Autonomous Prefecture, Yushu City, Longbao Town, 3330'13.54"N, 96²4'38.79"E, 4,602 m, 26 July 2019, J.T. Chen, X. Zhang \& T.H. Kuang HuangXH025-13 (holotype: KUN1498313!; isotype: KUN1498314!).

Diagnosis. Smelowskia sunhangii is easily distinguished from its closest relative S. tibetica by having densely hirsute (vs. glabrous or sparsely pubescent), elliptic to ovate-lanceolate (vs. oblong, suborbicular, or lanceolate) fruits undulate (vs. straight) along margin.

Description. Herbs $5-15 \mathrm{~cm}$ tall, covered with simple trichomes, canescent. Stems procumbent or ascending, densely white hirsute. Basal leaves densely hirsute; petiole $0.5-1.5 \mathrm{~cm}$ long, often ciliate basally; leaf blade ovate or narrowly oblong in outline, 1-pinnatifid, 1-4 × 1-2.5 cm; cauline leaves similar to basal, reduced in size upwards. Racemes bracteate throughout, distal bracts subsessile. Sepals oblong, 1-2 $\times$ $0.5-0.8 \mathrm{~mm}$, hirsute. Petals obovate, $2-3.2 \times 0.9-1.4 \mathrm{~mm}$, claw ca. $1.5 \mathrm{~mm}$ long. Fruit elliptic to ovate-lanceolate, densely white hirsute, $5-10 \times 3-5 \mathrm{~mm}$, undulate along margin, appressed to rachis. Seeds light to dark brown, oblong, 0.9-1.2 $\times 0.4-0.6 \mathrm{~mm}$. Fl. Jul-Sep, fr. Aug-Oct.

Etymology. Smelowskia sunhangii is named after Prof. Sun Hang (1963-), director of the Kunming Institute of Botany (China) who conducted extensive research on plant taxonomy, biogeography, and evolutionary biology and made outstanding contributions towards understanding the plant diversity of China. Vernacular name: The Chinese name is given as “毛果藏荠” (máo guǒ zàng jì), referring to the densely hirsute fruit of the new species.

Distribution. China (Qinghai, Tibet [Xizang], Fig. 1).

Paratypes. China. Tibet: Lhasa, Damxung County, Gangla Mountain, 3041'6.77"N, 916'16.88"E, 4,802 m, 27 July 2018, D.G. Zhang DengT051-14 (KUN). Qinghai: Yushu Tibetan Autonomous Prefecture, Yushu City, 32¹7'20.62"N, 9550'15.29"E, 4,848 m, 23 July 2019, P.J. Liu \& H.H. Shi deng7262 (KUN); Yushu 

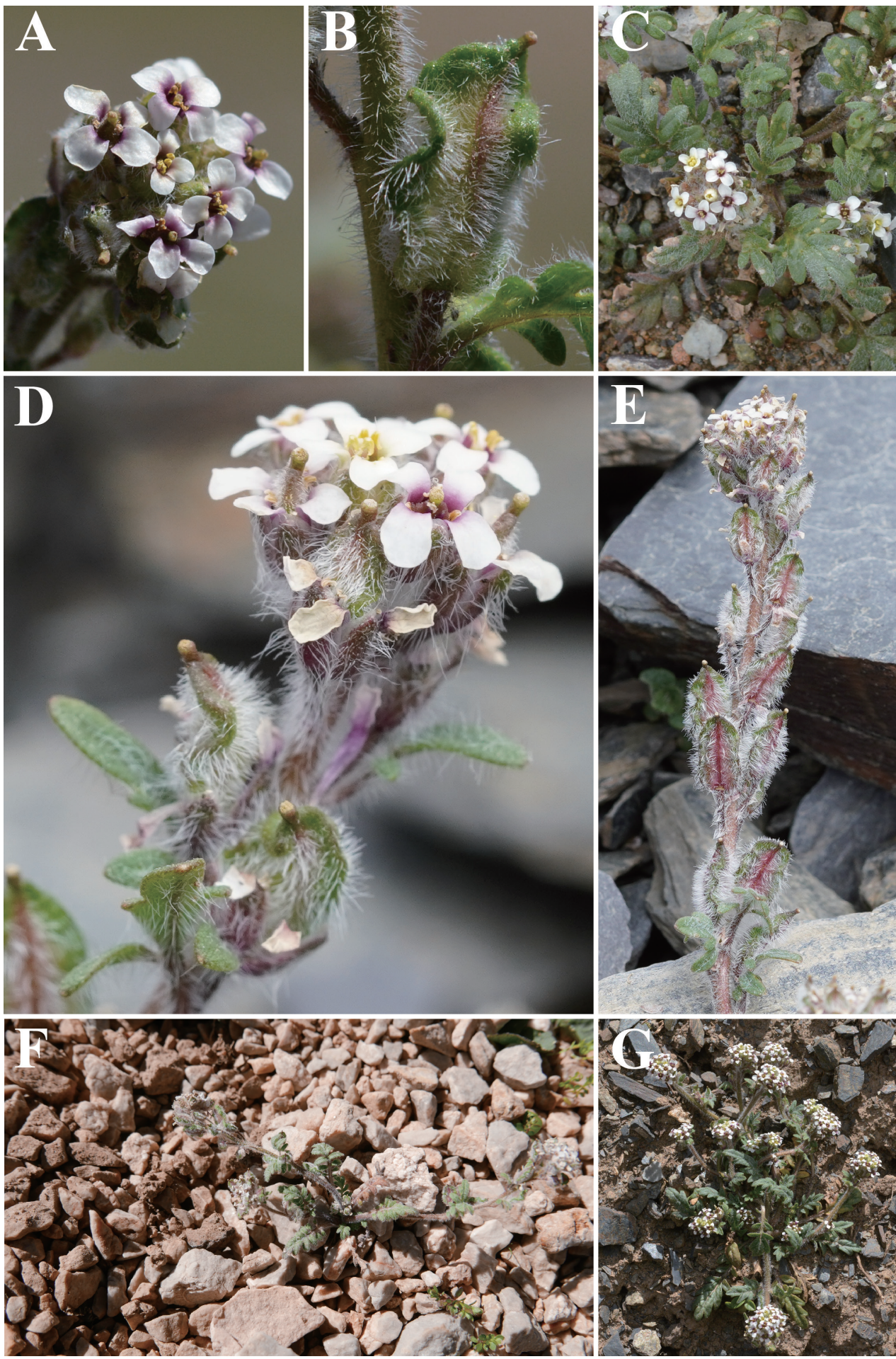

Figure 3. Smelowskia sunhangii T. Deng, X.J. Zhang \& J.T. Chen A flower B fruit C leaves and flowers $\mathbf{D}$ inflorescence $\mathbf{E}$ infructescence $\mathbf{F}, \mathbf{G}$ plants and habitat. 
中国科学院昆明植物研究所标本馆

Herbarium, Kunming Institute of Botany, CAS

采集号(Coll. No.): HuangXH025-13

采集日期(Date): 2019-07-26

采集者(Collector)：陈㣞通，张尤，匡田㩆 J.T. Chen. X. Zhang \& T.H. Kuang

采集地(Locality)：青海玉树市隆宝镇 Longbao Town, Yushu City, Qinghai Province

经纬度(Long. / Lat.); $96^{\circ} 24^{\prime} 38.79^{\prime \prime}$ E, $33^{\circ} 30^{\prime} 13.54^{\prime \prime} \mathrm{N}$

生境(Habitat)：高山碎石坡 Aipine scree slopes

海拔(AIt): $4602 \mathrm{~m}$

植物习性(Habit): 草本 Herb 株高(High): $5 \mathrm{~cm}$

频度(Frequency): 低

形态描述(Desc.): 果实密被白色长毛

野外篮定(ID in the field)：藏泺属 Hedinia
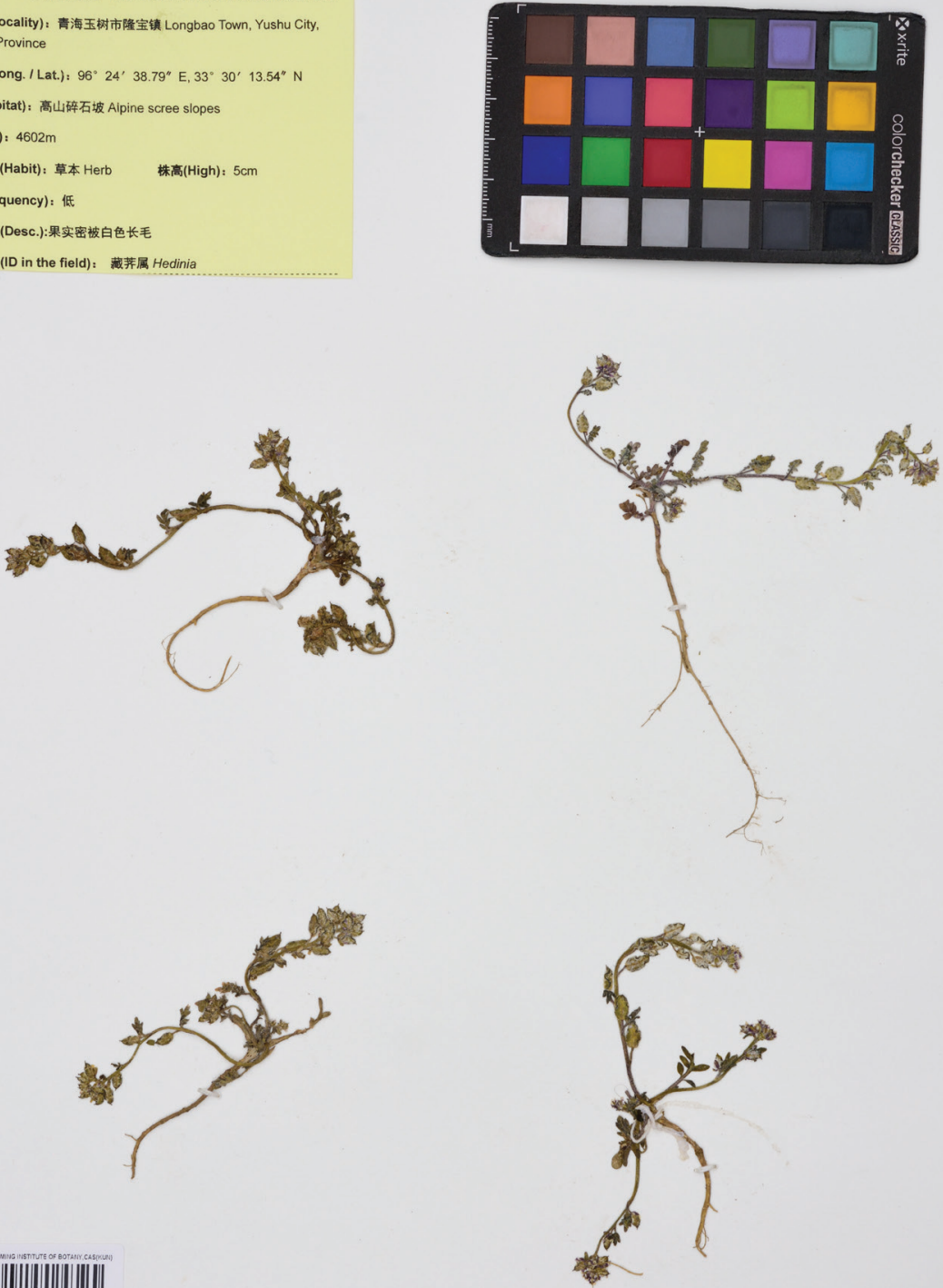

陈俊通，张旭，匡田辉 J.T. Chen, $X$. Zhang \& T.H. Kuang Huang XH025-13

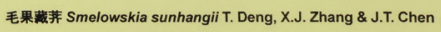
鉴定人(Det.):邓涛, 张信坚, 陈俊通(T. Deng, X.J. Zhang \& J.T. Chen )

Figure 4. Photograph of the holotype of Smelowskia sunhangii T. Deng, X.J. Zhang \& J.T. Chen (KUN1498313). 
Tibetan Autonomous Prefecture, Chindu City, 31 July 2019, T. Deng, X.H. Huang, Z.Y. Lv \& L.J. Li DengT128-9 (KUN); Yushu Tibetan Autonomous Prefecture, T. Deng, X.H. Huang, Z.Y. Lv \& L.J. Li DengT105-23 (KUN); Yushu Tibetan Autonomous Prefecture, Qumarlêb County, 2 September 2013, J.W. Zhang, B. Yang \& H.L. Chen Zh641 (KUN).

\section{Smelowskia tibetica (Thomson) Lipsky}

Basionym: Hutchinsia tibetica Thomson, Hooker's Icon. Pl. 9: t. 900. 1852. TYPE: WESTERN TIBET. Lanak Pass, 18-19,000 ft [ca. 5,480-5,790 m], Thomas Thomson s.n. (holotype: K!).

Synonyms: Hedinia tibetica (Thomson) Ostenf. in Hedin, S. Tibet 6: fig. 2. 1922.

Hedinia lata Xue L.He \& C.H.An, Acta Phytotax. Sin. 34(2): 205. 1996. TYPE: TIBET. Ando, alt. 4,750 m, on stony mountain slopes, 14 August 1963, J.X. Yang 2220 (holotype: WUK, n.v.).

Hedinia rotundata C.H.An, Acta Bot. Boreali-Occid. Sinica 10: 325. 1990. TYPE: XINJIANG. The west of Altum Mountains, Qimantag, 2,700 m, 25 July 1984, Zhang Li-Yun 84-A-411 (holotype: XJA!)

Hedinia taxkargannica G.L.Zhou \& C.H.An, Acta Bot. Boreal.-Occid. Sin. 10: 323. 1990. TYPE: XINJIANG. Tajik Autonomous County of Taxkargan Vaka, in alpina desert steppe zone, July 1986, An Zheng-xi N. 268 (holotype: XJA!)

Description. Detailed descriptions of the species are found in the Flora of China (Zhou et al. 2001), Nepal (Al-Shehbaz and Watson 2011), and the entire Himalayan Region (Al-Shehbaz 2015). Therefore, there is no need to repeat it here.

Distribution. China (Gansu, Qinghai, Sichuan, Tibet, Xinjiang, Fig. 1), Bhutan, India, Kyrgyzstan, Nepal, Tajikistan.

Chinese specimens examined. China. Tibet: Baingoin County, 15 August 1988, S.G. Wu, H. Ohba, Y.H. Wu \& Y. Fei No. 4095 (KUN); Lhasa, Damxung County, Namtso, 25 July 2018, D.G. Zhang, Y. Wu \& H. Ye ZDG18-9 (KUN); Nagqu, Sog County, 28 July 2018, D.G. Zhang, Y. Wu \& H. Ye ZDG23-7 (KUN); Nagqu, Sog County, 28 July 2018, D. G. Zhang, Y. Wu \& H. Ye ZDG24-24 (KUN); Nagqu, Shenza County, 3 August 1987, B.S. Li \& D. Zheng 10888 (PE); Nagqu, Biru County, 3 September 1976, D.D. Tao 11181a (KUN); Nagqu, Anduo County, 10 September 2008, J.H. Chen, H.F. Zhuang \& D. T. Liu Yangyp-Q-0258 (KUN); Nagqu, Baqing County, 26 June 2016, J.P. Yue, Z. Zhou \& H.L. Chen YZC226 (KUN); Nagqu, Anduo County, 21 August 2009, J.H. Chen, H.F. Zhuang \& P. Tashi YangYP-Q-2166 (KUN); Ngari, Rutog County, 29 July 1987, B.S. Li, D. Zheng 10848 (PE); Changdu, Jomda County, 1 August 2004, D.E. Boufford, J.H. Chen, S.L. Kelley, J.Li, R. H. Ree, H. Sun, J.P. Yue \& Y.H. Zhang 31531 (KUN); Changdu, Riwoqê County, 11 August 2004, D.E. Boufford, J.H. Chen, S.L. Kelley, J. Li, R.H. Ree, H. Sun, J.P. Yue \& Y.H. Zhang 32037 (KUN). Qinghai: Yushu Tibetan Autonomous Prefecture, Nangqên County, 24 July 1965, Y.C. Yang 1261 (KUN); Yushu Tibetan Autonomous Prefecture, Nangqên County, 24 July 2019, 
X. Zhang, J.T. Chen \& T.H. Kuang HuangXH018-9 (KUN); Yushu Tibetan Autonomous Prefecture, Nangqên County, 23 July 2019, X. Zhang, J.T. Chen \& T.H. Kuang HuangXH015-20 (KUN); Yushu Tibetan Autonomous Prefecture, Yushu City, 23 July 2019, P.J. Liu \& H.H. Shi deng7261 (KUN); Yushu Tibetan Autonomous Prefecture, Zadoi County, 25 July 2019, P.J. Liu \& H.H. Shi deng7359 (KUN); Haibei Tibetan Autonomous Prefecture, Menyuan Hui Autonomous County, 26 July 2008, Y.H. Wu LJQ-QLS-2008-0115 (KUN); Haibei Tibetan Autonomous Prefecture, Menyuan Hui Autonomous County, 18 June 2018, X.X. Zhu \& Y.M. An ZXX18140 (KUN); Golog Tibetan Autonomous Prefecture, Madoi County, 31 July 2011, S.L. Chen, Q.B. Gao \& F.Q. Zhang ChenSL1379 (KUN); Golog Tibetan Autonomous Prefecture, Baima County, 29 August 2013, J.W. Zhang, B. Yang \& H.L. Cheng Zh537 (KUN); Golog Tibetan Autonomous Prefecture, Darlag County, 10 August 1993, H.B.G. 1033 (PE); Haixi Mongol and Tibetan Autonomous Prefecture, Golmud City, 11 September 2008, H.Y. Feng LiuJQ-08KLS-139 (KUN); Haixi Mongol and Tibetan Autonomous Prefecture, Golmud City, 19 August 2010, X.M. Tian, Z.Q. Wang \& J.B. Zou LiuJQ-Txm10-097 (KUN); Haixi Mongol and Tibetan Autonomous Prefecture, Golmud City, Fenghuo mountain, 18 August 2010, X.M. Tian, Z.Q. Wang \& J.B. Zou Liujq-Txm10-074 (KUN); Haixi Mongol and Tibetan Autonomous Prefecture, Golmud City, Ulan Moron, 22 August 1990, Yang Jingsheng 402 (KUN). Xinjiang: Bayin'gholin Mongol Autonomous Prefecture, Ruoqiang County, 10 August 1988, S.G. Wu, H. Ohba, Y.H. Wu \& Y. Fei 2678 (KUN); Bayin'gholin Mongol Autonomous Prefecture, Hejing County, 16 August 1958, J.N. Zhu \& A.R. Li 6543 (KUN); Kashgar Prefecture, Taxkorgan Tajik Autonomous County, 11 August 2008, J. Qiu \& J.J. Feng LiuJQ0171 (KUN).

\section{Acknowledgements}

We deeply thank Mr. Dai-Gui Zhang for taking part in the field collections. We are also grateful to Ms. Juan Qiu, of Xinjiang Agricultural University, for providing the type specimen of Hedinia taxkargannica. This study was supported by grants from the Second Tibetan Plateau Scientific Expedition and Research (STEP) program (2019QZKK0502), the Strategic Priority Research Program of Chinese Academy of Sciences (XDA20050203), the Key Projects of the Joint Fund of the National Natural Science Foundation of China (U1802232), the Youth Innovation Promotion Association of Chinese Academy of Sciences (2019382), the Young Academic and Technical Leader Raising Foundation of Yunnan Province (2019HB039), the Chinese Academy of Sciences "Light of West China" Program, and the Biodiversity Survey, Monitoring and Assessment (2019HB2096001006).

\section{References}

Al-Shehbaz IA (2012) A generic and tribal synopsis of the Brassicaceae (Cruciferae). Taxon 61(5): 931-954. https://doi.org/10.1002/tax.615002 
Al-Shehbaz IA (2015) Brassicaceae. In: Hong DY (Ed.) Flora of Pan-Himalaya (Vol. 30). Science Press and Cambridge University Press, 594 pp.

Al-Shehbaz IA, Warwick SI (2006) A Synopsis of Smelowskia (Brassicaceae). Harvard Papers in Botany 11(1): 91-99. https://doi.org/10.3100/1043-4534(2006)11[91:ASOSB]2.0.CO;2 Al-Shehbaz IA, Watson MF (2011) Cruciferae (Brassicaceae). In: Watson MF, Akiyama S, Ikeda H, Pendry CA, Rajbanadri KR, Shrestha KK (Eds) Flora of Nepal (Vol. 3). Royal Botanic Garden Edinburgh, Edinburgh, 108-181.

Al-Shehbaz IA, Beilstein MA, Kellogg EA (2006) Systematics and phylogeny of the Brassicaceae: An overview. Plant Systematics and Evolution 259(2-4): 98-120. https://doi. org/10.1007/s00606-006-0415-z

Appel O, Al-Shehbaz IA (2003) Cruciferae. In: Kubitzki K, Bayer C (Eds) The Families and Genera of Vascular Plants (Vol. 5). Springer-Verlag, Heidelberg, Berlin, 75-174. https:// doi.org/10.1007/978-3-662-07255-4_17

Carlsen T, Elven R, Brochmann C (2010) The evolutionary history of Beringian Smelowskia (Brassicaceae) inferred from combined microsatellite and DNS sequence data. Taxon 59(2): 427-438. https://doi.org/10.1002/tax.592008

German DA, Chen WL (2009) Notes on the family Brassicaceae in China. Journal of Systematics and Evolution 47(3): 202-219. https://doi.org/10.1111/j.1759-6831.2009.00022.x

Guindon S, Dufayard JF, Lefort V, Anisimova M, Hordijk W, Gascuel O (2010) New algorithms and methods to estimate maximum-likelihood phylogenies: Accessing the performance of PhyML 3.0. Systematic Biology 59(3): 207-221. https://doi.org/10.1093/ sysbio/syq010

He XL, An ZX (1996) A new species of the genus Hedinia Ostenf. (Cruciferae) from Xizang. Zhiwu Fenlei Xuebao 34(2): 205-206.

Huelsenbeck JP, Ronquist F (2001) MRBAYES: Bayesian inference of phylogenetic trees. Bioinformatics (Oxford, England) 17(8): 754-755. https://doi.org/10.1093/bioinformatics/17.8.754

Thiers B (2018) Index Herbariorum: A global directory of public herbaria and associated staff. New York Botanical Garden Virtual Herbarium, The Bronx. http://sweetgum.nybg.org/ih/ Kiefer M, Schmickl R, German DA, Mandáková T, Lysak MA, Al-Shehbaz IA, Franzke A, Mummenhoff K, Stamatakis A, Koch MA (2014) BrassiBase: Introduction to a novel knowledge database on Brassicaceae evolution. Plant Cell Physiology 55(1): e3[1-9]. https://doi.org/10.1093/pcp/pct158

Liu LM, Du XY, Guo C, Li DZ (2020) Resolving robust phylogenetic relationships of core Brassicaceae using genome skimming data. Journal of Systematics and Evolution jse.12666. https://doi.org/10.1111/jse.12666

O'Kane SL, Schaal BA, Al-Shehbaz IA (1997) The origins of Arabidopsis suecica (Brassicaceae) as indicated by nuclear rDNA sequences. Systematic Botany 21(4): 559-566. https://doi. org/10.2307/2419615

Posada D (2008) JModeltest: Phylogenetic model averaging. Molecular Biology and Evolution 25(7): 1253-1256. https://doi.org/10.1093/molbev/msn083

Schulz OE (1936) Cruciferae. In: Engler A, Harms H (Eds) Die Natürlichen Pflanzenfamilien (Ed. 2, 17B). Verlag von Wilhelm Engelmann, Leipzig, 227-658. 
Sudhir K, Glen S, Koichiro T (2016) MEGA7: Molecular Evolutionary Genetics Analysis Version 7.0 for Bigger Datasets. Molecular Biology and Evolution 33(7): 1870-1874. https:// doi.org/10.1093/molbev/msw054

Warwick SI, Al-Shehbaz IA, Sauder CA, Murray DF, Mummenhoff K (2004) Phylogeny of Smelowskia and related genera (Brassicaceae) based on nuclear its DNA and chloroplast trnL intron DNA sequences. Annals of the Missouri Botanical Garden 91: 99-123.

White TJ, Bruns T, Lee S, Taylor J (1990) Amplification and direct sequencing of fugal ribosomal RNA genes for phylogenetics. In: Innis M, Gelfand D, Sninsky J, White T (Eds) PCR Protocols: A Guide to Methods and Applications. Academic Press, San Diego, 315-322. https://doi.org/10.1016/B978-0-12-372180-8.50042-1

Zhou GL, An ZX (1990) A study on the genus Hedinia. Acta Botanica Boreali-Occidentalis Sinica 10: 320-325.

Zhou TY, Lu LL, Yang G, Al-Shehbaz IA (2001) Brassicaceae. In: Wu CY, Raven PH (Eds) Flora of China (Vol. 8). Science Press (Beijing) and the Missouri Botanical Garden Press (St. Louis), 193 pp. 